Review

\title{
Pancreatic cancer: statistics and treatment in the Russian Federation
}

\author{
Yury O. Zharikov ${ }^{1}$, Svetlana S. Zemlyakova ${ }^{2}$, Yana V. Kiseleva ${ }^{1}$, Tatiana S. Zharikova ${ }^{1}$, Sevak G. Antonyan ${ }^{3}$, \\ Kirill A. Tupikin ${ }^{4}$, Vladimir N. Nikolenko ${ }^{1,5}$ \\ ${ }^{1}$ I.M. Sechenov First Moscow State Medical University (Sechenov University), Moscow, Russia \\ ${ }^{2}$ Izmerov Research Institute of Occupational Health, Moscow, Russia \\ ${ }^{3}$ N.V. Sklifosovsky Research Institute for Emergency Medicine, Moscow, Russia \\ ${ }^{4}$ A.I. Evdokimov Moscow State University of Medicine and Dentistry, Moscow, Russia \\ ${ }^{5}$ M.V. Lomonosov Moscow State University, Moscow, Russia
}

Received 4 October 2019, Revised 12 September 2020, Accepted 5 October 2020

(C) 2019, Zharikov Yu.O., Zemlyakova S.S., Kiseleva Y.V., Zharikova T.S., Antonyan S.G., Tupikin K.A., Nikolenko V.N.

(C) 2019, Russian Open Medical Journal

\begin{abstract}
Pancreatic cancer (PC) is one of the most fatal types of oncological disease in the world and is an extremely aggressive cancer with a poor prognosis. The objective of this review was to analyze the domestic data of the incidence of PC in the Russian Federation and to analyze the protocols that are used for the management of this group of patients in Russian clinical centers. For the analysis of the literature sources, the data in the elibrary.ru database published in the period from 2015 to 2019 were used. The methodology that was used in each study was examined in order to ensure its reliability, and these data were selected as potential sources of evidence for the preparation of national recommendations. The study results influence the level of evidence assigned to the publication. Updates to the national recommendations are conducted at least once every three years, and these updates depend on new information about the diagnosis and management of patients with PC.
\end{abstract}

Keywords: pancreatic cancer, incidence, Russian clinical centers, management, prognosis.

Cite as Zharikov YuO, Zemlyakova SS, Kiseleva YV, Zharikova TS, Antonyan SG, Tupikin KA, Nikolenko VN. Pancreatic cancer: statistics and treatment in the Russian Federation. Russian Open Medical Journal 2020; 9: e0415.

Correspondence to Yury O. Zharikov. 8/2, Trybetskaya street, Moscow, 119991, Russia. Phone: +79999121145. E-mail: dr zharikov@mail.ru.

\section{Introduction}

The management of the treatment of oncological patients in the Russian Federation is carried out according to the national recommendations developed by the Association of Oncologists of Russia and the Russian Society of Clinical Oncology (http://www.oncology.ru/association/clinicalguidelines/2018/rak podzheludochnoy zhelezy pr2018.pdf) [1]. These recommendations are legislative in nature and are mandatory in practical medicine. The recommendations are based on evidence collected through searches in electronic databases, analyses of modern scientific research on the problem of pancreatic cancer in both the Russian Federation and abroad [2, $3]$, and the generalization of practical Russian experiences and foreign experts.

The objective of this review was to analyze the domestic data on the incidence of PC in the Russian Federation and to analyze the protocols that are used in Russian clinical centers for the management of this group of patients. The immediate and longterm results of the treatment of this difficult group of patients were also analyzed. For the analysis of the literature sources, the data in the elibrary.ru database published in the period from 2015 to 2019 were used.
The search strategy included studies of all of the available information on the following keywords: pancreatic cancer, incidence, diagnostics, treatment and prognosis.

Pancreatic cancer (PC) is one of the most fatal types of oncological disease in the world, and it is an extremely aggressive cancer with a poor prognosis $[2,4,5]$. Currently, PC is also a significant medical and social problem throughout the world due to the clinical features of the disease, including late disease manifestation, the complexity of the diagnostics and the rather low effectiveness of treatment for this disease [6]. In most cases, this pathology is diagnosed at the late stages in patients when radical surgery is irrelevant. Over the past several decades, the incidence and mortality of PC in Russia have exhibited high rates without a significant downward trend.

According to the literature, PC can develop from exocrine (95\% of cases) or endocrine (5\% of cases) organ cells [7]. In most cases, it presents histologically as epithelial ductal adenocarcinoma (75$90 \%$; in rare cases, it presents as squamous cell carcinoma, mesenchymal tumors or lymphomas. Rare histological types can include glandular-squamous, clear-cell, giant-cell, cricoid-cell, mucinous, anaplastic and oncocytoma. The morphological verification rate in Russia was 48.8\% in 2013 [4, 5, 8]. 
Malignant tumors can form in different parts of the pancreas, including the head (56-74\% of cases), the body (10-18\%) and the tail $(6-8 \%)$, with total pancreatic lesions being observed in $6-28 \%$ of patients $[8,9]$.

The frequent localization of a tumor in the head of the pancreas results in the typical manifestation of the disease via the development of obstructive jaundice due to the tumor obstruction of the common bile duct. At the time of the diagnosis of pancreatic head cancer, this complication is present in the overwhelming majority (85\%) of patients [5]. The use of radical surgery has the potential risk of severe postoperative complications on the background of untreated obstructive jaundice.

\section{Incidence}

The analysis of the incidence data demonstrates that the annual primary incidence rate of PC is approximately even throughout the world. The annual incidence rate is 11 cases per 100,000 in the United States, 16 per 100,000 in Japan and England and 18 per 100,000 in Italy and Sweden [10]. The incidence rate of PC in Russia is 8.6 per 100,000; in Moscow, the incidence rate is 11.4 per 100,000 . Over the course of the past 50 years, the incidence rate has increased by 4 times $[8,11]$. According to Russian cancer registry data, the primary incidence of pancreatic malignant neoplasms has exhibited a constant upward trend in the last several decades [12].

The system for the obligative registration of all malignant tumors (MTs) was created in 1953 in Russia, unlike in other countries. This system makes it possible to adequately assess the oncological situation throughout the country. However, this information is not sufficient for analytical epidemiological studies [4].

Over 15,000 new cases of PC are registered in Russia annually, and this type of cancer represents $3.2 \%$ of all newly emerging neoplasms in men and $2.6 \%$ in women [9]. In Russia, PC is the 10th most frequently detected tumor in men and 12th most frequent in women. Moreover, PC ranks 6th and 7th among the causes of death from cancer in men and women, respectively. In 2013, 14,842 cases of PC were diagnosed, with 16,117 people having died from this disease. According to the data of the P.A. Hertsen Moscow Oncology Research Center, the annual number of deaths from PC is $3-7 \%$ higher than the number of diseases registered in living patients, i.e., there is a high rate of detection of the disease at autopsy [13].

Pancreatic tumors have the highest index of untimely diagnosis (with the average Russian indicator being $60.5 \%$ in 2016). In 2016, the proportion of patients in Russia with stage III IV pancreatic cancer was $79.5 \%$, and the mortality rate during the first year after the diagnosis of PC was $68.3 \%[13,14]$.

PC represents $10 \%$ of all malignant tumors of the gastrointestinal tract and ranks in 3rd place among this type of oncopathology. PC is diagnosed in $18 \%$ of all diseases of the pancreas and ranks in 4th place in the causes of death in cancer patients [9].

According to Russian data, PC is equally common among males and females living in the territory of the Russian Federation [9]. The increased incidence of this disease is observed in most cases at the age of 50-59 years in men and at the age of $70-79$ years in women.
On average, stage I-II PC is diagnosed in $13.3 \%$ of cases in the Russian Federation, and stage IV PC is diagnosed in $59.4 \%$ of cases. According to the registry (2001-2012), stage I PC is diagnosed in $0.9 \%$ of cases, stage II PC is diagnosed in $5.8 \%$ of cases, stage III PC is diagnosed in $12.3 \%$ of cases, and stage IV PC is diagnosed in $80.9 \%$ of cases. It should be noted that no stage is indicated in $40 \%$ of cases, and it can be suggested that the neglected forms of PC are a considerable portion of this group, if we evaluate the disease via one-year mortality (43.6\%) [4]. Metastases to the lymph nodes and organs are diagnosed in $82 \%$ of patients at the time of diagnosis, and only $18 \%$ of patients do not exhibit metastases [9].

\section{Risk factors}

Smoking is the main risk factor for the development of PC. It is suggested that a third of all of the cases of this disease are provoked by the abuse of tobacco. This is because tobacco smoke is saturated with polycyclic aromatic hydrocarbons, which are powerful stimulators of tumor growth. At the time of autopsy, smokers are observed to have hyperplastic changes in the pancreatic duct system [4].

Obesity, as a result of disturbances in the system of homeostasis, leads to a decrease in immunity and to the development of metabolic immunosuppression. It is assumed that obesity involves feedback mechanisms that support the development of inflammation mediated by the production of tumor necrosis factor alpha and interleukin-6. Additionally, the disruption of autophagy, which contributes to the stress response of the endoplasmic reticulum, as well as defects of apoptosis and mitochondrial dysfunction, are also involved in this condition [15].

Although most cases of PC occur sporadically, approximately $10 \%$ of PC cases are hereditary $[2,16]$. A relative risk model has been developed in the USA for nongenetic and genetic risk factors for PC based on monitoring data from more than 3,000 patients with $\mathrm{PC}$ and the same number of control individuals. The model included current smoking (risk with other factors $=2.20$ ), alcohol consumption $>54 \mathrm{ml}$ ( 3 drinks/day) (risk: 1.45), obesity (body mass index $>30 \mathrm{~kg} / \mathrm{m} 2$ ) (risk: 1.26 ), diabetes mellitus $>3$ years (risk: 1.80 ), family history of $P C$ (risk: 1.60 ), non-O ABO genotype (BB versus $O O$ genotype) (risk: 1.58), rs3790844 (chr1q32.1) (risk: 1.29), rs401681 (5p15.33) (risk: 1.18) and rs9543325 (13q22.1) (risk: 1.27). The specificities of this model were $58 \%, 57 \%$ and $61 \%$ for nongenetic factors, genetic factors and both factors, respectively [4].

\section{Diagnostics}

The problem of the diagnosis of oncological disease at an early stage is particularly important for our country [17]. The continuing trend in the diagnosis of PC at a late stage shapes the results of treatment, namely, the unsatisfactory results [9].

Patients with PC initially receive treatment for chronic pancreatitis in approximately $5 \%$ of cases. On average, malignant tumors are verified after no less than 2 months. Therefore, it is recommended to consider the diagnosis of $\mathrm{PC}$ in persons older than 40 years with a supposed diagnosis of "chronic pancreatitis", and especially in at-risk patients, such as severe smokers and alcohol abusers [4].

The primary method for the diagnosis of PC involves the following instrumental diagnostics: ultrasound, multispiral computed tomography and $\mathrm{MRI}[8,18,19,20]$. Both computed 
tomography and MR are highly sensitive for the detection of pancreatic cancer, with sensitivity values up to $96 \%$ and $93.5 \%$, respectively [20]. As a rule, the following diagnostic methods are used: ultrasound tomography with Doppler sonography of the great vessels, multispiral computed tomography with contrast enhancement, magnetic resonance imaging, angiography (celiacography, upper mesentericography and recurrent mesentericoportography), endoscopic ultrasound tomography and intraportal ultrasound tomography [21, 22]. Morphological research is the basis of the diagnosis of PC [7]. Foreign recommendations (NCCN, 2020) for the treatment of pancreatic adenocarcinoma adhere to the same principles of diagnosis, visualization and staging in this disease.

Furthermore, the diagnosis of PC is verified on the basis of at least two radiological methods; in addition, with the presence/absence of distant metastases and tumor invasion into the great vessels, the arterial architecture of the hepatopancreatobiliary zone can be estimated [23]. The details of the patient examination should involve obtaining detailed information about the condition of the great vessels, especially the celiac trunk, the common hepatic artery, the superior mesenteric artery (SMA) and the splenic and superior mesenteric veins [21].

3D reconstruction can improve the diagnostic capabilities for the localization of a tumor lesion [18]. As was demonstrated by a group of researchers from the A.V. Vishnevsky Institute of Surgery, postprocessing work with $\mathrm{CT}$ images with the construction of $3 \mathrm{D}$ models makes it possible to improve the preoperative assessment of resectability, to more accurately determine the localization of the tumor and to evaluate the degree of vascular invasion.

\section{Neoadjuvant therapy}

Surgery for primary resectable PC is recommended without preoperative chemotherapy and/or radiotherapy. The initiation of treatment with conservative methods is allowable only during clinical studies [7]. In the article "Opinions and use of neoadjuvant therapy for resectable, borderline resectable, and locally advanced pancreatic cancer: international survey and case-vignette study" by Heinrich S. et al. [24], it was demonstrated that the majority (75.4\%) of participants believed that borderline resectable pancreatic cancer has a high risk for R1 resection and that neoadjuvant therapy may increase the rate of R0 resection (79.8\%) and improve oncological patient selection (84.2\%). In addition, chemotherapy was regarded as being useful to convert locally advanced to resectable tumors by $55.7 \%$ of the respondents. This fact demonstrates that it is necessary to further study the effect of neoadjuvant chemotherapy on the course of the disease.

Neoadjuvant regional chemotherapy, radical R0 surgeries and courses of adjuvant regional chemotherapy were prescribed to 53 patients with pancreatic head adenocarcinoma in the study by D.A. Granov and coauthors [25]. Regional chemotherapy was developed with gemcitabine in a suspension of lipiodol in the gastro-duodenal artery, which was supplemented by oxaliplatin infusions. Postembolization syndrome developed in 10 (18.8\%) patients; hematologic toxicity was observed in 13 (24.5\%) patients and was scored at 1-2 points on the Common Toxicity Criteria. Anemia was detected in 5 (9\%) patients, neutropenia was detected in 2 (4\%) patients, and thrombocytopenia was observed in 1 patient. Moreover, nausea was observed in 11 (20.7\%) patients, and vomiting was observed in $10(18.8 \%)$ patients. These results indicate the use of this regimen of regional chemotherapy as a safe step in the combined treatment of patients with pancreatic head adenocarcinoma.

Oil chemoembolization (OCE) of the vessels supplying a pancreatic tumor in neoadjuvant and intraoperative modes may be a prospective treatment. According to data from Russian researchers, the use of this technique in some cases allowed for the reduction of the size of the tumor and provided ablative radical surgical treatment due to the prolonged selective chemotherapeutic effect on local tumor micrometastases. According to data from the AM Granov Russian Scientific Center of Radiology and Surgical Technologies, the combination of neoadjuvant OCE of tumors of the pancreatic head, gastropancreatoduodenal resection and adjuvant regional chemotherapy with gemcitabine made it possible to achieve an average life expectancy (ALE) of $22.3 \pm 2.1$ months, as well as 1-, 2and 3 -year survival rates of $80 \%, 59 \%$ and $43 \%$, respectively. These indicators were significantly better than the post-operative situations without the use of regional therapy, in which case the ALE was $8.4 \pm 2.1$ months and the indicators of 1-, 2- and 3-year survival were $71 \%, 20 \%$ and $13 \%$, respectively $(p<0.05)$ [26].

The highest probability of achieving resectability was achieved by using the FOLFIRINOX chemotherapy regimens or a combination of gemcitabine and nab-paclitaxel $[3,7,24]$.

\section{Surgical treatment}

The decision on a treatment of nonmetastatic PC is based on the assessment of the resectability of the primary tumor $[3,7]$.

A radical operation on the background of untreated obstructive jaundice may increase the risk of the development of severe postoperative complications. In this regard, preliminary biliary drainage (PBD) is as a rule performed at the first stage of treatment. In most cases, the indication for PBD is considered a level of total bilirubin above $60-100 \mu \mathrm{mol} / \mathrm{L}$. At the same time, the PBD procedure can also increase the risk of complications and can delay the operation; therefore, the use of this procedure in this scenario is debatable [27]. Until now, the operability of patients with PC has remained low, and the prognosis has been poor. Tumor invasion into the retroperitoneal tissue or the involvement of the great vessels in the malignant process have often been observed in the absence of detectable metastases. In this regard, only $10-20 \%$ of all patients are candidates for radical surgery [3]. Almost $50 \%$ of patients exhibit distant tumor metastases, and $35 \%$ of patients exhibit locally extended disease [6, 21]; thus, these patients can be treated via alternative local methods [6].

Pancreatoduodenal resection (PDR) is a complex operation and is performed for malignant tumors of the pancreas, the terminal section of the common bile duct and the major duodenal papilla. This procedure is rarely used for complications of chronic pancreatitis. The mortality rate after this operation has been steadily decreasing. At the same time, the frequency of postoperative complications remains high and can reach $50-60 \%$ $[28,29]$. One way to improve the results of PDR is to optimize the pre- and postoperative management of patients and surgical techniques $[3,23]$. Currently, there are three main access points: traditional laparotomy, laparoscopic procedures and robotic techniques (RA).

Tumors T1-T2 are as a rule an indication for robot-associated PDR. The traditional access point permits the operation of patients with any tumor size in the absence of distant metastases or invasions into the celiac trunk and into the superior mesenteric 
artery [23]. 3D reconstruction improves the ability to determine the localization of the tumor, indications for access, and the content of the surgery [18]. Researchers from the A.V. Vishnevsky Institute of Surgery demonstrated that duodenopancreatectomy (DPE) is most likely to occur when ductal adenocarcinoma comprises more than $31.8 \%$ of the total pancreas volume according to 3D CT models.

The results of the study by Hartwig W. et al. demonstrated that the median survival and 5-year overall survival rates were reduced in patients who had extended pancreatectomies compared with those patients undergoing a standard resection (16.1 months versus 23.6 months and $11.3 \%$ versus $20.6 \%$, respectively). Older age, G3/4 tumors, two or more positive lymph nodes, macroscopically positive resection margins, duration of surgery of 420 minutes or more and blood loss of $1000 \mathrm{ml}$ or more were independently associated with decreased overall survival. In conclusion, the authors indicated that the preferred long-term outcome was achieved in some patients and that DPE should only be performed in a highly selective group of patients [30].

Despite the aggressive and disabling features of DPE, this operation is the only way to prolong the lives of patients in some situations [30]. According to data from the Mayo Clinic, the life expectancy after DPE can reach two years when the volume reaches RO and when there is an absence of metastatic lymph nodes at the time of the operation [21].

In some cases, a circular resection of the diseased celiac trunk and of the common hepatic artery is performed with the simultaneous resection of the superior mesenteric vein (SMV) and/or the portal vein (PV), after which plastic surgery with synthetic prostheses is performed [31]. The duration of the clamping of the portal vein varies from 10-14 minutes during the creation of a direct end-to-end anastomosis and can extend to 21 minutes during the prosthesis repair. The resection of the celiac trunk and the common hepatic artery with ligation of the base of the celiac trunk and the common hepatic artery before the site of the gastroduodenal artery and without grafting of the aortohepatic arterial vascular bed is possible in cases of sufficiently developed arterial collaterals between the basins of the superior mesenteric and gastroduodenal arteries. The blood supply of the liver is provided by the gastroduodenal artery [21, 32].

R. Koehler et al. proved that after the ligation of the celiac trunk, the collaterals from the superior mesenteric artery through the pancreatoduodenal artery significantly expand in diameter in 4 hours, and the blood flow of the liver is fully restored within 6 months; these data are based on the results of an angiographic study [33]. The other danger of the resection of the celiac trunk is the potential for disturbance of the blood supply to the stomach. The blood supply of the stomach is provided by the right gastroepiploic and right gastric arteries after the ligation of the common hepatic artery (before the appearance of the gastroduodenal artery); as a rule, this is an adequate blood supply [32]. In rare cases, this type of blood supply is inadequate [21].

A total pancreatectomy is possible and is performed in cases of primary multiple lesions (cancers of the pancreatic body, pancreatic tail and major duodenal papilla). This operation is a complex surgical procedure that leads to severe metabolic changes in the patient. However, when it is performed according to clearly defined indications, the operation can allow for an acceptable level of postoperative complications, improving longterm survival with a satisfactory quality of life [34].
Currently, the greatest experience in laparoscopic treatment of PC has been accumulated by specialists of the A.S. Loginov Moscow Clinical and Research Center of the Moscow Department of Health Care. Data analysis has demonstrated that laparoscopic pancreatoduodenal resection (LPDR) was performed most often (245 operations), including both the classical (Whipple procedure) and pylorus-sparing variants. In 13 cases, the operation included resection and vascular reconstruction of the portal vein and the superior mesenteric vein, with various modifications. The various types of preoperative biliary decompression were performed in patients with obstructive jaundice. In most cases, the operation was performed for ductal cancer of the pancreas head. Total laparoscopic pancreatoduodenal resection (Whipple procedure) was performed in $197(80.4 \%)$ cases, with a pylorus-preserving pancreatoduodenal resection performed in $48(19.6 \%)$ cases. Urgent histological examinations were performed in all cases, with the resection border of the common bile duct and the pancreas, the medial border of the pancreas and the tissues adjacent to the superior mesenteric artery and vein being examined. Failure of the pancreatojejunostomy after LPDR was observed in 30 (12.2\%) patients, which is comparable with the number of failures of open interventions (10-45\%). It should be noted that there was a complete absence of wound problems, pneumonia and phlebothrombosis among the complications of surgeries using laparoscopic technologies. The absence of wound complications also excludes the development of postoperative hernia, which is inevitably associated with wound infection [28].

Additionally, in this study, 52 patients ( 35 women and 17 men) underwent different variations of laparoscopic distal resection of the pancreas (LDR). The average age of the patients was $51 \pm 13.4$ years. In most cases, distal cancer of the pancreas was the indication for surgery. LDR was performed completely laparoscopically in $50(96.2 \%)$ cases. The duration of the operation was $228 \pm 74$ minutes, the volume of blood loss was $40 \pm 50 \mathrm{ml}$, and the hospital stay was $8 \pm 5$ days. Complications occurred in 19 (38\%) patients. Grade B pancreatic fistula occurred in 21 (42\%) patients [28].

\section{Complex chemoradiation therapy}

Adjuvant chemotherapy is the only method that can be used to increase patient survival after $\mathrm{R} 0$ resection $[7,18]$.

In the postoperative period, chemotherapy (CT) courses are performed with gemcitabine monotherapy, according to the standard scheme, in most cases. Radiation therapy (RT) in a total focal dose of $50-56 \mathrm{~Gy}$ is performed in the postoperative period after nonradical (R2) operations [7].

Until recently, gemcitabine monotherapy was considered the standard of chemotherapy for this pathology; however, at the present time, combined chemotherapy regimens (FOLFIRINOX and nab-paclitaxel in combination with gemcitabine) are more effective and are included in clinical practice [3]. These chemotherapy regimens are limited by their relatively high toxicities; thus, it is impossible to use these drugs in weakened patients and in patients with serious comorbidities [35].

For locally advanced pancreatic cancer, FOLFIRINOX (leucovorin and fluorouracil plus irinotecan and oxaliplatin) has been reported to increase the pooled median overall survival to 24.2 months, which is longer than the 15.0 months for patients who were treated with gemcitabine [36] 


\section{Tactics for unresectable tumors}

PC is characterized by an aggressive course and a high metastatic potential. The main treatment for locally advanced and metastatic PC is chemotherapy. Currently, the treatment options for patients with unresectable, locally advanced PC are very limited, and the prognosis for these patients is very poor. The standard for treating patients with inoperable PC is monochemotherapy with gemcitabine, but the response rate is only $5-15 \%[2,5-7]$.

Patients with a mutation in the BRCA1 or BRCA2 genes, as well as hereditary cancer burden (having two or more relatives of 1-3 degrees of kinship who have suffered from breast, ovarian or pancreatic cancer), are recommended to use the FOLFIRINOX combination or a combination of gemcitabine with a platinum derivative (cisplatin, carboplatin or oxaliplatin) [7].

The development of new methods for local destruction of unresectable, intra-abdominal localization tumors began at the end of the twentieth century in many countries throughout the world, with such methods helping stop the symptoms of the tumor process, improve quality of life indicators and improve survival time. These methods include radiofrequency and microwave ablation, high-intensity focused ultrasound therapy, cryoablation, irreversible electroporation, stereotactic radiation therapy and photodynamic therapy [6].

Since 2012, in the A.V. Vishnevsky Institute of Surgery, patients with locally advanced, unresectable PC have undergone the cryodestruction of PC with laparotomic access by the use of the "Cryo-MT", "CRYO-01" (ELAMED), and cryoapplicators $(2-5 \mathrm{~cm})$ in order to improve the quality of life and patient survival. Local cryodestruction was supplemented with the formation of bypass anastomoses. All patients underwent adjuvant chemotherapy, which was supplemented with regional chemoembolization in 10 cases. No fatal outcomes were reported. In the immediate postoperative period, complications were noted in 14 (38.8\%) patients, and severe complications were noted in $13.6 \%$ of patients. There was either the complete disappearance of pain syndrome (39.2\%) or its significant reduction $(41.6 \%)$ after cryodestruction. The survival rates of patients after $6,12,24$ and 36 months were $92 \%, 84 \%, 48 \%$ and $14 \%$, respectively, and the median survival was 18.2 months. According to researchers, some survival increase was noted upon combination with chemotherapy [37].

In 2018, a review of the safety and efficacy of arterial chemoembolization in patients with locally advanced PC was published. Chemoembolization of the gastroduodenal artery was performed in 52 patients with unresectable, locally advanced PC without distant metastases (T3-4N0-1M0). Overall, 109 cycles of chemoembolization were performed (range 1 to 7; average 2). Technically, in the presence of multiple small-diameter vessels supplying the tumor from the proximal part of the gastroduodenal artery (GDA), a metal spiral was installed into the GDA, which reduced the blood flow distal to the site of the discharge of these arteries. Subsequently, chemoembolization was introduced, which included a suspension of gemcitabine at $200-400 \mathrm{mg} / \mathrm{m} 2$ in 2-5 $\mathrm{ml}$ of superfluid lipiodol. The overlap of the blood flow to the untargeted vessels by the use of balloon catheters (redistributive embolization of the pancreatic arteries, except for the caudal artery) was utilized to reduce the need for bypass surgery. Manifestations of postembolization syndrome were stopped for 1 day with the help of conservative treatment. Chemotherapeutic toxicity of degree I was noted in 44 (85\%) patients, and gastrointestinal toxicity of degrees II - III was noted in 8 (15\%) patients. The clinical effects, such as weight increases and pain reduction, were achieved after two cycles in $90 \%$ and $71 \%$ of patients, respectively. The average life expectancy of the entire group was 9.9, with a median of 6.7 months. However, these indicators were higher in the 14 patients who received three or more cycles of chemoembolization, with an average life expectancy of 14.4 months and a median of 9.6 months [5].

The use of radiation therapy (RT) is possible in cases of local recurrence after surgical treatment, as well as in cases of continued growth of the primary unresectable tumor after CT in the absence of distant metastases. The continued applications of CT and RT in such situations is not defined. Irradiation is performed in single focal doses of 1.8-2.0 Gy to total focal doses of 45-54 Gy, in combination with capecitabine at a dose of 1600 $\mathrm{mg} / \mathrm{m} 2 /$ day per os daily during the entire irradiation period [7].

\section{Prognosis}

PC is characterized by high aggressiveness and the lowest survival rates among cancers, with a one-year mortality rate reaching $79.1 \%$, five-year survival rate of $6-11 \%$ and median survival of 14 months [5, 21]. The only option for radical treatment of this group of patients is surgery. However, at the time of the final diagnosis, many patients have unresectable, locally advanced tumors involving the celiac trunk/superior mesenteric artery, and distant metastases may also be detected. The median survival of such patients is $3-6$ months $[3,4,27]$.

Stabilization of the process is noted in no more than $1.8-3 \%$ of patients [9]. The clinical and morphological factors such as histological type and degree of differentiation of tumor cells have the most significant effect on the survival of patients [27].

In their study, Wang $\mathrm{H}$ et al. demonstrated that patients with a higher tumor grade had much worse prognoses than did those with lower tumor grades. Most PC patients were diagnosed at a relatively advanced stage, and clinical staging has been accepted as being a prognostic factor for cancer treatment. In addition, their results demonstrated that younger patients who were diagnosed at an early stage had the best chance of survival, and the survival rate was observed to decline with increasing age [38].

According to Patyutko Yu I, the one-year and two-year survival rates were $59.1 \%$ and $21.5 \%$, respectively, the median was 13 months, and the maximum life expectancy was 57 months in patients with locally advanced ductal carcinoma of the body and of the tail of the pancreas via the application of advanced resection procedures of the organ with resection of the celiac trunk. Complete and persistent pain relief was observed in $100 \%$ of patients who underwent distal subtotal resections of the pancreas with resection of the celiac trunk and neurodissection [21].

The increased incidence of cancer is due to both the aging of the population, decreases in the quality of life and in the ecological situation and improvement of cancer diagnostics. The rate of incidence of late stage disease remains high, with the frequency of the diagnostics of the disease in the presence of distant metastases also being high. Thus, this scenario likely characterizes the unsatisfactory state of preventative work in the general medical network. The main role in the modern study of all health care organizations in the Russian Federation involves the continuing development of new methods for the early diagnosis of background pathology, precancerous conditions, and early-stage 
cancer and the implementation of modern technologies in the diagnosis and treatments of pancreatic cancer.

\section{Conclusion}

In summary, significant developments continue to be made in the diagnosis and management of patients with PC. The methodology that was used in each study was examined in order to ensure its reliability, and these data were selected as potential sources of evidence for the preparation of national recommendations in the Russian Federation, which are also consistent with international trends. Currently, PC patients are best managed by a multidisciplinary team consisting of gastroenterologists, pancreatobiliary surgeons, radiologists and oncologists. Advances in cross-sectional imaging have led to more accurate diagnosis and staging methods. Additionally, surgical resection remains the only curative treatment for this disease, and improved surgical techniques including venous and artery reconstruction may lead to an increase in the percentage of resectable patients. New chemotherapy protocols, with or without the use of radiation therapy, have led to an increase in overall survival, although this strategy remains palliative. The discovery of biomarkers, as well as the monitoring of people with risk factors that would facilitate the earlier identification of pancreatic cancer, would greatly affect patient management and prognosis.

\section{Conflict of interest}

There is no conflict of interests

\section{References}

1. Russian Oncology Association. Pancreas cancer. Clinical recommendations. 2018. 36 p. Russian. http://www.oncology.ru/association/clinicalguidelines/2018/rak podzheludochnoy zhelezy pr2018.pdf

2. Levi ST, Gough BL, Darcy CE, Petrelli NJ, Bennett JJ. Pancreatic resections: 30 and 90-day outcomes in octogenarians. Surgical Oncology 2020; in press. https://doi.org/10.1016/j.suronc.2020.01.002

3. Wittel UA, Lubgan D, Ghadimi M, Belyaev O, Uhl W, Bechstein WO, et al. Consensus in determining the resectability of locally progressed pancreatic ductal adenocarcinoma - results of the Conko-007 multicenter trial. BMC Cancer 2019; 19(1): 979. https://doi.org/10.1186/s12885-019-6148-5.

4. Reshetnikov OV, Openko TG, Kurilovich SA. Pancreatic cancer (data of the Registry in Novosibirsk, risk factors, prevention options). Voprosy Onkologii 2016; 62(3): 433-439. Russian. https://www.elibrary.ru/item.asp?id=26254267.

5. Kozlov AV, Tarazov PG, Pavlovskij AV, Polikarpov AA, Rozengauz EV, Popov SA, Granov DA. Arterial chemoembolization in patients with locally advanced pancreatic cancer. Grekov's Bulletin of Surgery. 2018; 177(1): 31-36. Russian. https://doi.org/10.24884/0042-4625-2018177-1-31-36.

6. Moskvicheva LI, Petrov LO, Sidorov DV. The possibilities of modern methods of ablation in non-resectable locally advanced pancreatic cancer. Research'n Practical Medicine Journal. 2018; 5(2): 86-99. Russian. https://doi.org/10.17709/2409-2231-2018-5-2-10.

7. Pokataev IA, Alieva SB, Gladkov OA, Zagainov VE, Kudashkin NE, Patyutko Yul, et al. Practical recommendations for drug treatment of pancreatic cancer. Malignant Tumoursis 2017; 7(3-S2): 367-379. Russian. https://www.elibrary.ru/item.asp?id=34866776.

8. Vinnik YS, Serova EV, Bobkova AV, Tsedrik N.I., Tsedrik A.A., Repina E.V. et al. Clinical case of diagnosis of pancreatic cancer. Russian medical journal 2016; 24(8): 525-527. Russian. https://www.elibrary.ru/item.asp?id=26237078.
9. Avdyushina AA. Problems of modern diagnosis and adequate treatment of patients with malignant tumors of pancreas in Smolensk region within the period of the years of 2008-2010. Smolenskij Medicinskij Almanah 2016; (1): 8-11. Russian. https://www.elibrary.ru/item.asp?id=26001782.

10. Siegel RL, Miller KD, Jemal A. Cancer statistics, 2016. CA Cancer J Clin 2016; 66(1): 7-30. https://doi.org/10.3322/caac.21332.

11. Gordienko VP, Mazharova OA, Korobkova TN. Some aspects of epidemiology of malignant tumors in the far Eastern federal district. Amur Medical Journal 2018; 3(23): 38-41. Russian. https://doi.org/10.22448/AMJ.2018.3.38-41.

12. Kaprin AD, Kostin AA, Nikiforov PV, Egorov VI, Grishin NA, Lozhkin MV, et al. Pancreatoduodenectomy: learning curve within single multi-field center. Pirogov Russian Journal of Surgery 2018; (4): 17-23. Russian. https://doi.org/10.17116/hirurgia2018417-23.

13. The state of cancer care to the population of Russia in 2016. Kaprin AD, Starinsky VV, Petrova GV, eds. Moscow, Russia: P. Hertsen Moscow Oncology Research Institute - Branch of the National Medical Radiology Research Centre of the Ministry of Health of the Russian Federation, 2017; $236 \quad$ p. Russian. https://www.elibrary.ru/item.asp?id=29676386.

14. Okladnikova E.V., Ruksha T.G. Analysis of hospital morbidity for pancreatic cancer in Krasnoyarsk Krai. Siberian journal of Oncology 2015; (6): 61-67. Russian. https://www.elibrary.ru/item.asp?id=25055726.

15. Gukovsky I, Li N, Todoric J, Gukovskaya A, Karin M. Inflammation, autophagy, and obesity: common features in the pathogenesis of pancreatitis and pancreatic cancer. Gastroenterology 2013; 144(6): 1199-1209.e4. https://doi.org/10.1053/j.gastro.2013.02.007.

16. Kondratieva LG, Chernov IP, Zinoviev MV, Egorov VI, Kopantsev EP, Sverdlov ED. Heterogeneity of expression of master regulator of embryonic development SOX9 in patients with pancreatic cancer. Dokl Biochem Biophys 2018; 481(4): 208-211. https://doi.org/10.1134/s1607672918040087.

17. Putin V.V. Instructions on implementing the address to the Federal Assembly. Topical issues of economics, management and law: collection of scientific works (yearbook) 2018; (1): 4-79. Russian. https://elibrary.ru/item.asp?id=34865577.

18. Nerestyuk Yal, Karmazanovsky GG, Kubyshkin VA, Krieger AG Khairieva AV. The role of $3 \mathrm{D}-\mathrm{CT}$ in surgery for pancreatic ductal adenocarcinoma: post-processing and tissue volume calculation. Pirogov Russian Journal of Surgery 2017; (4): 36-40. Russian. https://doi.org/10.17116/hirurgia2017436-40.

19. Tulin PE, Dolgushin MB, Nevzorov DI, Kochergin PV, Patyutko YI. $\mathrm{PET} / \mathrm{CT}$ in the diagnosis of pancreatic cancer: literature review. Medical Visualization 2018; (1): 57-67. Russian. https://doi.org/10.24835/1607-0763-2018-1-57-67.

20. Chu LC, Goggins MG, Fishman EK. Diagnosis and Detection of Pancreatic Cancer. Cancer J 2017; 23(6): 333-342. https://doi.org/10.1097/ppo.0000000000000290.

21. Patyutko Yul, Abgaryan MG, Kudashkin NE, Kotelnikov AG. Celiac trunk resection in patients with pancreatic cancer and severe pain syndrome. Pirogov Russian Journal of Surgery 2016; (11): 8-18. Russian. https://doi.org/10.17116/hirurgia2016118-18.

22. Yousaf MN, Chaudhary FS, Ehsan A, Suarez AL, Muniraj T, Jamidar P, et al. Endoscopic ultrasound (EUS) and the management of pancreatic cancer. BMJ Open Gastroenterol 2020; 7(1): e000408. https://doi.org/10.1136/bmjgast-2020-000408.

23. Kriger AG, Gorin, DS, Kaldarov AR, Paklina OV, Raevskaya MB Berelavichus SV, et al. Pancreaticoduodenectomy: Methodological aspects and results. P.A. Herzen Journal of Oncology 2016; 5(5): 15-21. Russian. https://doi.org/10.17116/onkolog20165515-21.

24. Heinrich $S$, Besselink $M$, Moehler $M$, van Laethem JL, Ducreux $M$, Grimminger $P$, et al. Opinions and use of neoadjuvant therapy for resectable, borderline resectable, and locally advanced pancreatic 
cancer: international survey and case-vignette study. BMC Cancer 2019; 19(1): 675. https://doi.org/10.1186/s12885-019-5889-5.

25. Granov D.A., Polikarpov A.A., Pavlovskiy A.V., Moiseenko V.E., Popov S.A. Evaluation of intra-arterial chemotherapy safety by using of gemcitabine and oxaliplatin in combined treatment of pancreatic head adenocarcinoma. Annals of HPB Surgery 2017; 22(2): 54-59. Russian. https://doi.org/10.16931/1995-5464.2017254-59.

26. Polikarpov AA, Pavlovsky AV, Gulo AS, Popov AS, Tarazov PG, Granov DA. Long-term results of combined $x$-ray endovascular surgical treatment of patients with ductal adenocarcinoma of the pancreatic head. Grekov's Bulletin of Surgery 2013; 172(4): 40-43. Russian. https://elibrary.ru/item.asp?id=20147224.

27. Mikhailov IV, Bondarenko VM, Nesterovich TN, Kudryashov VA, Achinovich SL. Surgical Treatment Results of Cancer of the Pancreatic Head, Depending on Preoperative Biliary Drainage. Novosti Khirurgii 2017; 25(3): 286-291. Russian. https://doi.org/10.18484/23050047.2017.3.286

28. Khatkov IE, Tsvirkun VV, Izrailov RE, Vasnev OS, Tyutyunnik PS, Mikhnevich MV, Baychorov ME, Andrianov AV. Laparoscopic interventions in the pancreas: an 11-year experience of a specialized center. Almanac of Clinical Medicine 2018; 46(6): 640-647. Russian. https://doi.org/10.18786/2072-0505-2018-466-640-647.

29. Voskanyan SE, Naydenov EV, Uteshev IY, Artemiev AI, Udalov YD, Zabelin MV. The dependence of direct results of distal pancreatectomies on different pancreatic stump closure techniques. Grekov's Bulletin of Surgery 2018; 177(4): 23-27. Russian. https://doi.org/10.24884/0042-4625-2018-177-4-23-27.

30. Hartwig W, Gluth A, Hinz U, Koliogiannis D, Strobel O, Hackert T, et al. Outcomes after extended pancreatectomy in patients with borderline resectable and locally advanced pancreatic cancer. Br J Surg 2016; 103(12): 1683-1694. https://doi.org/10.1002/bjs.10221.

31. Voskanyan SE, Artemiev AI, Naydenov EV, Shabalin MV, Zabezhinsky DA, Kolyshev IYu. Results of application of the PTFE-conduits in the reconstruction of the main veins of the abdominal cavity mesentericportal system in locally advanced pancreatic cancer. Saratov Journal of Medical Scientific Research 2015; 11(4): 668-672. Russian. https://elibrary.ru/item.asp?id=25593074.

32. Egorov VI, Petrov RV, Starostina NS, Zhurina YA, Grigorievsky MV. Results of the modified Appleby procedure. Pirogov Russian Journal of Surgery 2016; (3): 9-17. Russian. https://doi.org/10.17116/hirurgia201639-17.

33. Koehler RE, Korobkin M, Lewis F. Arteriographic demonstration of collateral arterial supply to the liver after hepatic artery ligation. Radiology 1975; 117(1): 49-54 https://doi.org/10.1148/117.1.49.

34. Patyutko YI, Kudashkin NE, Kotel'nikov AG, Chistyakova OV. Total pancreatectomy for pancreatic cancer. Pirogov Russian Journal of $\begin{array}{llll}\text { Surgery 2016; } & \text { (9): }\end{array}$ https://doi.org/10.17116/hirurgia2016913-20.

35. Popova AS, Pokataev IA, Tyulyandin SA. Combination chemotherapy regimens in pancreatic cancer. Medical Council 2017; (6): 62-70. Russian. https://doi.org/10.21518/2079-701X-2017-6-62-70.

36. Suker M, Beumer BR, Sadot E, Marthey L, Faris JE, Mellon EA, et al. FOLFIRINOX for locally advanced pancreatic cancer: a systematic review and patient-level meta-analysis. Lancet Oncol 2016; 17(6): 801810. https://doi.org/10.1016/s1470-2045(16)00172-8.

37. Ionkin DA, Karelskaya NA, Stepanova YA, Zemskov VM, Kozlova MN, Zhavoronkova OA, Chzhao AV. Cryoablation for locally advanced pancreatic cancer. Annals of HPB Surgery 2018; 23(2): 37-49. Russian. https://doi.org/10.16931/1995-5464.2018237-49

38. Wang $H$, Liu J, Xia G, Lei S, Huang $X$, Huang $X$. Survival of pancreatic cancer patients is negatively correlated with age at diagnosis: a population-based retrospective study. Sci Rep 2020; 10(1): 7048. https://doi.org/10.1038/s41598-020-64068-3.
Authors:

Yury O. Zharikov - MD, PhD, MBA, Associate Professor, Department of Human Anatomy, Sechenov University, Moscow, Russia. https://orcid.org/0000-0001-9636-3807.

Svetlana S. Zemlyakova - MD, PhD, MBA, Associate Professor, Izmerov Research Institute of Occupational Health, Moscow, Russia. https://orcid.org/0000-0001-7084-6472.

Yana V. Kiseleva - Student, Medicine of the Future, Sechenov University, Moscow, Russia. https://orcid.org/0000-0002-0009-9245.

Tatiana S. Zharikova - MD, PhD, Senior Lecturer, Department of Human Anatomy, Sechenov University, Moscow, Russia. https://orcid.org/00000001-6842-1520

Sevak G. Antonyan - MD, PhD, Researcher, Department of Emergency Surgical Gastroenterology, N.V. Sklifosovsky Research Institute for Emergency Medicine, Moscow, Russia. https://orcid.org/0000-0003-1463$\underline{1244}$.

Kirill A. Tupikin - MD, PhD, Senior Researcher, Laboratory of Minimally Invasive Surgery, A.I. Evdokimov Moscow State University of Medicine and Dentistry, Moscow, Russia. http://orcid.org/0000-0001-5467-0737.

Vladimir N. Nikolenko - MD, PhD, Professor, Head of the Department of Human Anatomy, Sechenov University, Moscow, Russia; Head of the Department of Normal and Topographical Anatomy, Lomonosov Moscow State University, Moscow, Russia. https://orcid.org/0000-0001-9532-9957. 